\title{
Evaluation of human capital performance of the countries by CRITIC and COPRAS methods: an application on the members of the organization of the black sea economic cooperation
}

\author{
Mahmut Masca $^{1 *}$ \\ ${ }^{1}$ Department of Economics, Faculty of Economics and Administrative Sciences, Afyon Kocatepe \\ University, IIBF, ANS Kampus, Gazligol Yolu, Afyonkarahisar, Turkey
}

\begin{abstract}
This study aims to evaluate the members of the Black Sea Economic Cooperation Organization (BSEC) in terms of human capital performance using CRITIC (Criteria Importance Through Intercriteria Correlation) and COPRAS (Complex Proportional Assessment) methods. A hybrid method has been used in analysis. This integrated model consists of a combination of CRITIC and COPRAS methods. The CRITIC method was used to find the objective weights of the criteria. The COPRAS method was used to rank the countries according to their performance. The infant mortality rate (per 1,000 live births), unemployment rate (percentage of the total labour force), average life expectancy at birth, total (years), labour force participation rate (percentage of the total population aged 15-64), current health expenditure (percentage of GDP), internet users (percentage of the total population) and population aged 15-64 (percentage of the total population) are used as criteria for measuring the human capital of countries. $2000,2005,2010,2015$, and 2018 data of the countries were used in the study. According to the analysis result, Serbia, Greece, Romania in 2000, Greece, Romania, Bulgaria in 2005, Greece, Russia, Bulgaria, in 2010, Russia, Moldova, Bulgaria in 2015, Russia, Romania and Bulgaria in 2018 are the top three countries with the highest human capital performance. Countries with the lowest human capital performance are as follows: Azerbaijan, Albania, Armenia in 2000 and 2005; Azerbaijan, Armenia, Turkey, in 2010; Turkey, Azerbaijan, Albania in 2015 and 2018.
\end{abstract}

\section{Introduction}

When labour, capital, natural resources, and entrepreneurs, which are traditional production factors in countries, have difficulty expressing economic growth, new theories attempting to explain economic growth have emerged. While classical and neoclassical growth theories place a strong emphasis on physical capital in economic expansion, endogenous growth theories place a greater emphasis on information, technical progress, and human capital.

* Corresponding author: mmasca@aku.edu.tr 
Human capital equipment - knowledge and skill that people have and can use to create economic value - may be a more important predictor of long-term economic success than all other factors combined. It is possible to increase the country's income by effectively utilizing and developing this resource. Because human capital is critical not only for societal productivity, but also for the operation of political, social, and civil institutions [1].

Human capital development and efficient utilization are critical for developing and underdeveloped countries. Human capital development requires an educated and healthy society. Individuals' satisfaction with financial opportunities and social relationships is a necessary condition for the efficient evaluation of this capital.

Human capital investments were found to have many positive effects in most empirical studies on human capital, including increased productivity in the agricultural and industrial sectors, more equitable income distribution, increased employment opportunities, elimination of regional disparities, and so on [2]. It is critical to uncover the existing level of human capital and its capacity in order to assess the country's future growth potential.

Human capital performance of Black Sea Economic Cooperation Organization (BSEC) members will be compared in this study using the CRITIC (Criteria Importance Through Intercriteria Correlation) and COPRAS (Complex Proportional Assessment) methods. This integrated model is made up of CRITIC and COPRAS methods. COPRAS is one of the MultiCriteria Decision Making (MCDM) techniques. In the studies using MCDM techniques, the alternatives generally are ranked according to their performance for a specific time. This study has used five different years' data to see the progress countries recorded during the studied years. The data for the countries cover the years 2000, 2005, 2010, 2015, and 2018.

\section{Literature review}

There are numerous applications of the COPRAS method in the literature.

Zavadskas et al. [3] proposed the COPRAS method for evaluating building life cycles in order to choose the best alternative. Vilutien and Zavadskas [4] identified the most effective variant of a home maintenance work and its performance using this method. Zavadskas et al. [5] developed a housing credit access model using the COPRAS method. This method was used by Andrukevicius [6] to select the best contractor for the construction of a trade and entertainment centre. Kaklauskas et al. [7] evaluated contractors for the replacement of windows in the main building of Vilnius Gediminas Technical University. Viteikien and Zavadskas [8] evaluated the sustainability of residential areas in Vilnius City using the COPRAS method. Banaitiene et al. [9] used the COPRAS method to determine the life cycle of a building. Mulliner et al. [10] assessed the affordability of various housing locations by taking economic, environmental, and social factors into account. Adalı and Işık [11] used COPRAS method for air conditioner selection. Patel et al. [12] used CRITIC-COPRAS method for selection of electric motorcycles.

\section{Methodology}

Countries' human capital data has been obtained from the World Bank website. The infant mortality rate (per 1,000 live births), unemployment rate (percentage of the total labour force), average life expectancy at birth, total (years), labour force participation rate (percentage of the total population aged 15-64), current health expenditure (percentage of GDP), internet users (percentage of the total population) and population aged 15-64 (percentage of the total population) are used as criteria for measuring the human capital performance of countries. These criteria are generally used in empirical studies on human capital and most of them are accepted as indicator of human capital by international 
organization such as World Bank, the UN and OECD [13]. CRITIC and COPRAS methods were used in this study to determine the weights of criteria and rank countries based on the human capital performance. The CRITIC method was used to determine the weights of the criteria, and then the COPRAS method was used to compare the human capital performance rankings of the countries using the determined criteria importance levels.

\subsection{CRITIC method}

The importance levels of the criteria are deemed equal in some studies in the literature; in others, the importance levels of the criteria were established using methods based on subjective evaluations (AHP, SWARA, Fuzzy AHP) or techniques based on objective assessments (ENTROPI, CRITIC).

In this study, CRITIC method has been used to determine the importance level of criteria. The CRITIC method was first published in the literature in 1995, with a study by Diakoulaki et al [14]. It is a weighting method that uses both the standard deviation of the criteria and the correlation values between the criteria. The standard deviation of each criterion of the normalized matrix, as well as the correlation relationship between other criteria, are used to calculate the significance levels of the criteria [15].

The advantages of CRITIC method can be listed as follows [16]

1. The weights derived take into account both contrast intensity and conflict, which are both present in the decision problem's structure.

2. The developed method is based on an analytical examination of the evaluation matrix in order to extract all information contained in the evaluation criteria.

3. The method is easily transformable into an algorithmic form.

4. It is discovered that the weights derived from the CRITIC method embody the information transmitted by all the criteria participating in the multi-criteria problem. Furthermore, objective weights provide insight into the nature of the dilemmas created by the presence of conflicting criteria and allow for the inclusion of interdependent criteria.

The variables defined in the method's application stages are as follows:

$i$.decision alternative $(i=1,2, \ldots, \mathrm{m})$

j. evaluation criteria $(j=1,2, \ldots, n)$

$\mathrm{z}_{\mathrm{jj}}: \mathrm{j}$. according to the evaluation criteria $\mathrm{i}$. the value of the alternative

$\mathrm{z}_{\mathrm{j}}^{\max }: \mathrm{j}$. maximum value of decision alternatives according to criteria

$z_{j}^{\min }: j$. minimum value of decision alternatives according to criteria

$\mathrm{r}_{\mathrm{ij}}: \mathrm{j}$. according to the evaluation criteria $\mathrm{i}$. normalized value received by the alternative

$\sigma_{j}: j$. standard deviation value of the criterion $(j=1,2, \ldots n)$

$\mathrm{y}_{\mathrm{jk}}$ : correlation coefficients of criteria $\mathrm{j}$ and $\mathrm{k}$ relative to each other

$\mathrm{w}_{\mathrm{j}}: \mathrm{j}$. weight of evaluation criteria $(\mathrm{j}=1,2, \ldots \mathrm{n})$

The CRITIC method consists of three steps [17]:

Step 1: Organize the decision matrix, which includes all alternatives and criteria. The decision matrix is depicted in equation 1 below.

$$
C=\left[Z_{i j}\right]_{m x n}=\left[\begin{array}{cccc}
z_{11} & z_{12} & \cdots & z_{1 n} \\
z_{21} & z_{22} & \cdots & z_{2 n} \\
\vdots & \vdots & \vdots & \vdots \\
z_{m 1} & z_{m 2} & \cdots & z_{m n}
\end{array}\right]
$$

Step 2: Using equation 2 (utility-based criteria) and equation 3(cost-based criteria), all values in the decision matrix are normalized.

$$
r_{i j}=\frac{z_{i j}-z_{j}^{\min }}{z_{j}^{\max }-z_{j}^{\min }}
$$




$$
r_{i j}=\frac{z_{j}^{\max }-z_{i j}}{z_{j}^{\max }-z_{j}^{\min }}
$$

Step 3: Using equation 4, calculate the weight $\left(\mathrm{w}_{\mathrm{j}}\right)$ of each criterion, taking into account the criterion's standard deviation and the criteria's correlations with one another.

$$
w_{j}=\frac{s_{j}}{\sum_{k=1}^{n} s_{k}}, \quad \mathrm{j}=1,2 \ldots \ldots \mathrm{n} \quad \text { (4) }
$$

Equation 5 is used to calculate the value $\left(\mathrm{s}_{\mathrm{j}}\right)$ in the preceding equation.

$$
s_{j}=\sigma_{j} \sum_{k=1}^{n}\left(1-y_{j k}\right) \quad \mathrm{j}=1,2 \ldots \ldots \mathrm{n} \quad \text { (5) }
$$

\subsection{COPRAS method}

The COPRAS method was first published in 1996 in a study by Zavadskas and Kaklauskas [18]. The most important difference between COPRAS and other MCDM methods is that when comparing decision alternatives, it gives a percentage of how good or bad one alternative is compared to the other [15]. The COPRAS method can be used to evaluate quantitative and qualitative criteria, maximizing useful criteria in terms of criteria evaluation, and minimizing useless criteria.

The following are the benefits of the COPRAS method (19):

- When compared to other methods such as AHP and TOPSIS, the COPRAS method is much easier to use because it requires much less calculation.

- The COPRAS method can calculate both maximizing and minimizing criteria.

- This method improves the ability to compute both qualitative and quantitative criteria.

- The main advantage of the COPRAS method over other multi-criteria decision-making methods is the ability to demonstrate utility degree. When alternatives are compared, it can show which one is better or worse.

The variables in the method's application stages are defined as follows.

i.decision alternative $(\mathrm{i}=1,2, \ldots, \mathrm{m})$

j. evaluation criteria $(j=1,2, \ldots n)$

$w_{j}: j$. weight of the evaluation criterion $(j=1,2, \ldots n)$

$x_{i j}: j$. according to the evaluation criteria $i$. the value of the alternative $(j=1,2, \ldots, n)$

$\mathrm{d}_{\mathrm{ij}}: \mathrm{j}$. according to the evaluation criteria $\mathrm{i}$. normalized value received by the alternative $(\mathrm{j}=1,2, \ldots \mathrm{n})$

The COPRAS method has six steps [7]:

Step 1: Organize the decision matrix. Equation 6 depicts this matrix.

$$
D=\left[x_{i j}\right]_{m x n}=\left[\begin{array}{cccc}
x_{11} & x_{12} & \cdots & x_{1 n} \\
x_{21} & x_{22} & \cdots & x_{2 n} \\
\vdots & \vdots & \vdots & \vdots \\
x_{m 1} & x_{m 2} & \cdots & x_{m n}
\end{array}\right]
$$

Step 2: Using equation 7, the decision matrix is normalized.

$$
x_{i j}^{*}=\frac{x_{i j}}{\sum_{k=1}^{m} x_{i j}} \quad \mathrm{j}=1,2 \ldots \ldots \mathrm{n}
$$

Step 3: Using equation 8, calculate the weighted normalized decision matrix (D') by multiplying the weight value $\left(\mathrm{w}_{\mathrm{j}}\right)$ of each evaluation criterion by the elements of the normalized decision matrix. 


$$
D^{\prime}=\left[\begin{array}{cccc}
d_{11} & d_{12} & \cdots & d_{1 n} \\
d_{21} & d_{22} & \cdots & d_{2 n} \\
\vdots & \vdots & \vdots & \vdots \\
d_{m 1} & d_{m 2} & \cdots & d_{m n}
\end{array}\right]
$$

The normalized decision matrix is weighted using Equation 9.

$$
d_{i j}=x_{i j}^{*} \cdot w_{j}
$$

Step 4: For the decision problem's criteria, find the sum of the values in the weighted normalized decision matrix. $\left(\mathrm{S}_{+\mathrm{i}}\right)$ equality 10 is used to calculate the sum of the values in the normalized decision matrix weighted for maximization-oriented criteria, and $\left(\mathrm{S}_{-i}\right)$ equality 11 is used to calculate the sum of the values in the normalized decision matrix weighted for minimization-oriented criteria.

$$
\begin{gathered}
S_{+i}=\sum_{j=1}^{k} d_{+i j} \quad \mathrm{j}=1,2 \ldots \ldots \mathrm{k} \\
S_{-i}=\sum_{j=k+1}^{n} d_{-i j} \quad \mathrm{j}=\mathrm{k}+1, \mathrm{k}+2 . . \mathrm{n}
\end{gathered}
$$

Step 5: Using equation 12, calculate the relative importance value $\left(\mathrm{Q}_{\mathrm{i}}\right)$ for each decision alternative.

$$
Q_{i}=S_{+i}+\frac{S_{-\min } \sum_{i=1}^{m} S_{-i}}{S_{-i} \sum_{i=1}^{m} \frac{S_{-m i n}}{S_{-i}}}
$$

Step 6: Using equation 13, calculate the performance index values (Pi) for each decision alternative.

$$
P_{i}=\frac{Q_{i}}{Q_{\max }} 100 \quad(13)
$$

\section{Findings}

The CRITIC method was used to determine the significance levels of the criteria used to compare the human capital performances of the countries using data from the years 2000, 2005, 2010, 2015, and 2018, and then the COPRAS method was used to rank the human capital performances of the countries using the CRITIC method's criterion weights. Using multi-year data makes it possible to follow the progress of each country's performance during the years. The outcomes were also presented.

\subsection{CRITIC method results}

The CRITIC method was used to objectively determine the importance levels of criteria used in comparing countries' human capital performance levels. Table 1 shows the importance levels of the CRITIC method. Importance levels of criteria change from one year to another. But the most important criterion was determined as unemployment rate for all years studied.

Table 1. Importance Levels of Criteria

\begin{tabular}{|c|c|c|c|c|c|c|c|c|c|c|}
\hline \multirow{2}{*}{ Criteria } & \multicolumn{10}{|c|}{ Wj } \\
\cline { 2 - 11 } & $\mathbf{2 0 0 0}$ & Rank & $\mathbf{2 0 0 5}$ & Rank & $\mathbf{2 0 1 0}$ & Rank & $\mathbf{2 0 1 5}$ & Rank & $\mathbf{2 0 1 8}$ & Rank \\
\hline $\begin{array}{c}\text { CHE (\% } \\
\text { of GDP) }\end{array}$ & 0,13644 & 4 & 0,12712 & 6 & 0,15489 & 4 & 0,15970 & 2 & 0,14652 & 3 \\
\hline
\end{tabular}




\begin{tabular}{|c|c|c|c|c|c|c|c|c|c|c|}
\hline $\begin{array}{c}\text { IU (\% of } \\
\text { popula- } \\
\text { tion) }\end{array}$ & 0,1301 & 5 & 0,15052 & 3 & 0,15821 & 3 & 0,13302 & 5 & 0,13425 & 5 \\
\hline $\begin{array}{c}\text { LFPR, } \\
\text { total }\end{array}$ & 0,16391 & 2 & 0,15139 & 2 & 0,13424 & 5 & 0,13386 & 4 & 0,13305 & 6 \\
\hline $\begin{array}{c}\text { LE, total } \\
\text { (years) }\end{array}$ & 0,12361 & 6 & 0,14162 & 5 & 0,12467 & 6 & 0,15492 & 3 & 0,14052 & 4 \\
\hline $\begin{array}{c}\text { MR, in- } \\
\text { fant }\end{array}$ & 0,08988 & 7 & 0,09502 & 7 & 0,10139 & 7 & 0,12636 & 7 & 0,12294 & 7 \\
\hline PA 15-64 & 0,1533 & 3 & 0,14802 & 4 & 0,15921 & 2 & 0,13175 & 6 & 0,15557 & 2 \\
\hline UN, total & 0,20280 & 1 & 0,18632 & 1 & 0,16740 & 1 & 0,16040 & 1 & 0,16715 & 1 \\
\hline
\end{tabular}

CHE: Current Health Expenditure, IU: Internet Users, LFPR: Labour Force Participation Rate, LE: Life Expectancy, MR: Mortality Rate, PA: Population Aged, UN: Unemployment Rate

\subsection{COPRAS method results}

The scores and rankings of countries according to their human capital performance for the years studied are given in the Table 2.

Table 2. Scores and Rankings of Counties (2000, 2005, 2010, 2015, 2018)

\begin{tabular}{|c|c|c|c|c|c|c|c|c|c|c|}
\hline \multirow{2}{*}{ Countries } & \multicolumn{10}{|c|}{$\mathbf{P}_{\mathbf{i}}$} \\
\cline { 2 - 12 } & $\mathbf{2 0 0 0}$ & Rank & $\mathbf{2 0 0 5}$ & Rank & $\mathbf{2 0 1 0}$ & Rank & $\mathbf{2 0 1 5}$ & Rank & $\mathbf{2 0 1 8}$ & Rank \\
\hline Albania & 60,7238 & 11 & 65,16610 & 11 & 81,49276 & 8 & 77,23191 & 10 & 77,6722 & 10 \\
\hline Armenia & 61,6860 & 10 & 67,38054 & 10 & 77,98951 & 11 & 83,19220 & 7 & 79,36727 & 8 \\
\hline $\begin{array}{c}\text { Azerbai- } \\
\text { jan }\end{array}$ & 50,3983 & $\mathbf{1 2}$ & 61,02485 & $\mathbf{1 2}$ & 76,08184 & $\mathbf{1 2}$ & 77,10450 & 11 & 74,62983 & 11 \\
\hline Bulgaria & 74,2012 & 4 & 87,30469 & 3 & 94,04579 & 3 & 92,50434 & 3 & 97,4979 & 3 \\
\hline Georgia & 65,3768 & 9 & 69,71327 & 9 & 80,58613 & 9 & 80,87162 & 9 & 78,46883 & 9 \\
\hline Greece & 98,1126 & 2 & 100 & $\mathbf{1}$ & 100 & $\mathbf{1}$ & 82,39385 & 8 & 80,19116 & 7 \\
\hline Moldova & 65,7087 & 8 & 84,24737 & 6 & 90,84789 & 5 & 92,59147 & 2 & 85,79064 & 5 \\
\hline Romania & 81,0943 & 3 & 89,26912 & 2 & 94,01178 & 4 & 90,53039 & 4 & 97,83023 & 2 \\
\hline $\begin{array}{c}\text { Russian } \\
\text { Federa- } \\
\text { tion }\end{array}$ & 70,6738 & 6 & 86,83440 & 4 & 96,34494 & 2 & 100 & $\mathbf{1}$ & 100 & $\mathbf{1}$ \\
\hline Serbia & 100 & $\mathbf{1}$ & 84,70298 & 5 & 86,70520 & 7 & 86,41553 & 6 & 86,49355 & 4 \\
\hline Turkey & 72,5611 & 5 & 71,37908 & 8 & 78,99471 & 10 & 75,71007 & $\mathbf{1 2}$ & 74,3987 & $\mathbf{1 2}$ \\
\hline Ukraine & 65,7493 & 7 & 78,05228 & 7 & 87,98680 & 6 & 88,90021 & 5 & 84,74153 & 6 \\
\hline
\end{tabular}

According to the results, the countries with the highest performance are Serbia in 2000, Greece in 2005 and 2010, and Russian Federation in 2015 and 2018. It can be seen that after being in the first ranking in 2005 and 2010, Greece regressed to eighth ranking in 2015 and seventh ranking in 2018, possibly due to economic crises that started at that time. Turkey was in fifth ranking in 2000, eighth ranking in 2005, tenth ranking in 2010, and twelfth ranking in 2015 and 2018. Albania, Armenia, Azerbaijan, and Turkey are the most disadvantaged countries in terms of human capital for all studied years.

\section{Conclusion}

Human capital is increasingly becoming the primary driving force behind productivity and economic growth. A country's productivity must be increased in order to grow and expand per capita output and consumption, thereby improving living standards. In a globalized economy where countries compete for resources as well as markets, the need for productivity growth becomes even more pressing. Because productivity growth is increasingly dependent on the development and application of new technology, public policy must be oriented toward 
the expansion of human capital, the improvement of its quality, and the effectiveness with which it is utilized [13].

A combination of CRITIC and COPRAS methods are used in the comparison of BSEC counties. Using the CRITIC method, the most important criterion is determined as the "unemployment rate." As a result of the human capital performance ranking obtained by the COPRAS method, Serbia, Greece, Romania in 2000, Greece, Romania, Bulgaria in 2005, Greece, Russia, Bulgaria, in 2010, Russia, Moldova, Bulgaria in 2015, Russia, Romania and Bulgaria in 2018 are the top three countries with the highest human capital performance. Countries with the lowest human capital performance are as follows: Azerbaijan, Albania, Armenia in 2000 and 2005; Azerbaijan, Armenia, Turkey, in 2010; Turkey, Azerbaijan, Albania in 2015 and 2018.

Countries with low human capital performance need to take some macroeconomic measures, especially to decrease the unemployment rate and increase the labour force participation rate. In addition, the share of health expenditures in GDP should be increased for a healthier generation, low mortality rate, and high life expectancy.

\section{References}

1. World Economic Forum, The Human Capital Report, (2016), http://www3.weforum.org/docs/HCR2016_Main_Report.pdf

2. K. Eser, Ç. E Gökmen, Sosyal ve Beşeri Bilimler Dergisi, 2(1), 41-56 (2009)

3. E. K. Zavadskas, A. Kaklauskas, N. Kvederyte, Informatica, 12(1), 169-188 (2001)

4. T. Vilutienė, E. K. Zavadskas, J. Civ. Eng. Manag, 9(4), 241- 252 (2003)

5. E. K. Zavadskas, A. Kaklauskas, A. Banaitis, N. Kvederyte, Eur. J. Oper. Res., 155(2), 335-352 (2004)

6. A. Andruškevicius, A., Technol. Econ. Dev. Econ, 11(3), 158-169 (2005)

7. A. Kaklauskas, E. K. Zavadskas, S. Raslanas, R. Ginevicius, A. Komka, P. Malinauskas, Energy and Buildings, 38(5), 454-462 (2006)

8. M. Viteikiene, E. K. Zavadskas, J. Civ. Eng. Manag, 8(2), 149-155 (2007)

9. N. Banaitiene, A. Banaitis, A. Kaklauskas, E. K. Zavadskas, Omega, 36(3), $429-441$ (2008)

10. E. Mulliner, K. Smallbone, V. Maliene, Omega, 41(2), 270-279 (2013)

11. E Adali, A. Iş1k, MANAS J. Social Studies, 5(2), 124-138 (2016)

12. A. Patel, S. Jha, R. Soni, K. Fuse, Comparative study of MCDM Techniques COPRAS and TOPSIS for selection of Electric Motorcycles, in Proceedings of 7th International Conference on Industrial Engineering and Applications, 16-21 April 2020, Bangkok, ICIEA 2020, 54-59 (2020)

13. W. Yu, AJSS, 3(2), 161-172 (2015)

14. D. Diakoulaki, G. Mavrotas, L. Papayannakis, Comput. Operat. Res., 22(7),763-770 (1995)

15. E. Ayçin E., Multi Criteria Decision Making: Computer Applied Solutions, (Nobel Academic Publishing. 2019)

16. N. H. Zardari, K. Ahmed, S. M. Shirazi, Z. B. Yusop, Weighting Methods and their Effects on Multi-Criteria Decision-Making Model Outcomes in Water Resources Management, (Spiringer, 2015)

17. M. Madic, M. Radovanovic, UPB Sci. Bull. Series D, 77(2), 193-204 (2015) 
18. E. K. Zavadskas, A. Kaklauskas, A Multiple Criteria Evaluation of Buildings, (Technika: Vilnius, Lithuania, 1996)

19 E. Aksoy, N. Ömürbek, M. Karaatlı, Hacettepe Üniversitesi İktisadi ve İdari Bilimler Fakültesi, 4(33), 1-28 (2015) 